\title{
Pregnancy and live birth rates in women with endometriosis related infertility in Latvia
}

\author{
Jekaterina Avdotina $^{1 *}$, Aleksandra Mezecka-Oleinika ${ }^{1}, V_{i j a}$ Silina $^{1}, Z_{\text {Zane }}$ Vitina $^{2}$
}

\author{
${ }^{1}$ Department of Family Medicine, Rīga Stradinš̌ University, Rīga, Latvia \\ ${ }^{2}$ Department of Obstetrics, Gynecology and Reproductology, SIA Clinic EGV, Rīga, Latvia
}

Received: 28 January 2019

Accepted: 02 February 2019

\section{*Correspondence:}

Dr. Jekaterina Avdotina,

E-mail: jakaterinaavdotina@gmail.com

Copyright: () the author(s), publisher and licensee Medip Academy. This is an open-access article distributed under the terms of the Creative Commons Attribution Non-Commercial License, which permits unrestricted non-commercial use, distribution, and reproduction in any medium, provided the original work is properly cited.

\begin{abstract}
Background: Women with endometriosis experience painful symptoms and/or infertility, others have no symptoms at all. According to European Society of Human Reproduction and Embryology guidelines, surgery and assisted reproductive technologies (ART) are an appropriate treatment in cases of endometriosis-associated infertility. There are controversial data on the results of surgery and ART in patients with endometriosis.

Methods: Retrospective analysis including 99 infertile patients aged between 25 and 48 years old. All of them had laparoscopic surgery as the primary option. 51 of them undergoing in vitro fertilization or intracytoplasmic sperm injection or frozen embryo transfer from 2003 through 2018 at SIA 'Clinic EGV'.

Results: The mean age of women was $34.2 \pm 4.5$. In $56(33.5 \%)$ cases was only surgery with $28(50.9 \%)$ biochemical pregnancies and $26(48.1 \%)$ live birth. In $111(66.5 \%)$ cases there were surgery with ART with 48 (47.6\%) biochemical pregnancies and $23(22.7 \%)$ live birth. In 1 group patients mean age $30.7 \pm 4.6$ and 2 group with mean age $35.1 \pm 4.2(\mathrm{p}=0.000)$. It was found that there is significant difference between endometriosis phenotype, infertility type, duration of infertility, repeated laparoscopic surgery, ART cycles, retrieved oocyte count and biochemical pregnancy rate.

Conclusions: Patients with endometriosis related infertility should undergo surgical treatment as the primary option. Those patients who do not become pregnant after surgery must be treated with assisted reproductive technology. The optimal time to perform ART is first year after endometriosis surgery.
\end{abstract}

Keywords: Assisted reproductive technologies, Biochemical pregnancy, Endometriosis phenotypes, Endometriosis stage, Live birth, Surgery

\section{INTRODUCTION}

Endometriosis is defined as the presence of endometriallike tissue outside the uterus, which induces a chronic, inflammatory reaction. ${ }^{1}$ While some women with endometriosis experience painful symptoms and/or infertility, others have no symptoms at all. The exact prevalence of endometriosis is unknown, but estimates range from 2 to $10 \%$ within the general female population but up to $50 \%$ in infertile women. ${ }^{2,3}$ It is widely accepted that endometriosis alters fertility, but the exact pathophysiology of this effect remains unclear. Current views suggest multifactorial mechanisms, including inflammatory changes in peritoneal fluid altering sperm-oocyte interaction, reduced functional ovarian tissue, and hampered endometrial receptivity. ${ }^{4}$ Classification systems of endometriosis, developed by several professional organizations, traditionally have been based on lesion appearance, pelvic adhesions, and anatomic location of disease (that includes the revised American Society for Reproductive Medicine and, where appropriate, the Enzian and Endometriosis Fertility Index 
staging systems). ${ }^{5}$ Laparoscopic surgery is considered the first line diagnostic option for treating endometriosisrelated infertility from mild to severe patients. ${ }^{6,7}$ The benefit of surgical intervention for endometriosis was suggested by some authors to reduce risks of caesarean section, preterm birth, ante-partum haemorrhage, placental complications, and pre-eclampsia. ${ }^{8,9}$ Moreover, it is the only approach to clarify the diagnosis by the visible presence of typical lesions and histological confirmation. ${ }^{10}$ On the other hand, risks associated with surgical resection are serious complications like: postsurgical infection, iatrogenic damage of pelvic organs, and reduced ovarian reserve or ovulation frequency. ${ }^{11}$ Another approach to treat infertile women with endometriosis is with assisted reproductive technologies (ART). ${ }^{12}$ ART results vary according to reports. Several studies have shown a negative effect of endometriosis on in vitro fertilization (IVF) pregnancy outcome, but other studies have reported no effect. ${ }^{13-16}$ The purpose of this study is to observe laparoscopic surgery with assisted reproductive technology (ART) and laparoscopic surgery without ART on pregnancy rate and live birth rate in the treatment of endometriosis-associated infertility. Either, to identify the optimal time interval between laparoscopy and assisted reproductive technology; determine if there is an impact of the endometriosis stage, phenotype. And also, to determine whether the influence of women age, BMI, primary or secondary infertility, duration of infertility, abortion history, men factor (semen analysis), cycle day-3 levels (follicle-stimulating hormone (FSH), luteinizing hormone, and estradiol), retrieved follicle count, number of fertilized eggs, number of embryos, embryos transfer day on pregnancy and live birth rate.

\section{METHODS}

The research was carried out in SIA 'Clinic EGV', Riga, Latvia. The local ethics committee (Riga Stradiņš University ethics committee) of our institution approved the study protocol. All patients were diagnosed with laparoscopically and then confirmed histologically. Patients clinical and surgical data were analysed retrospectively. The study population consisted of 99 phenotyped endometriosis patients and all of them underwent laparoscopic treatment but only 51 women undergo in vitro fertilization (IVF)/intracytoplasmic sperm injection (ICSI)/frozen embryo transfer (FET) infertility treatment from 2003 through 2018. Endometriotic lesions were classified according to their stage (minimal (I), mild (II), moderate (III) and severe (IV)) and phenotype as superficial peritoneal endometriosis (SUP), ovarian endometrioma (OMA), and deeply infiltrating endometriosis (DIE). Patients were assigned to the group corresponding to the most severe lesion. Either, following data were recorded: age, height, weight, body mass index, primary or secondary infertility, duration of infertility, abortion history, men factor (semen analysis), cycle day-3 levels (folliclestimulating hormone (FSH), luteinizing hormone, and estradiol), retrieved follicle count, number of fertilized eggs, number of embryos, embryos transfer day. Patients were stimulated by a long gonadotropin-releasing hormone (GnRH) agonist (Diphereline, Zoladex) or short agonist or an antagonist protocol (Cetrotide, Orgalutran) depending on individual patient characteristics. Ovulation stimulations were conducted with recombinant FSH (Bravella, Elonva, Bemfola, Gonal-f, Ovaleap, Puregon) or human menopausal gonadotropin (Merional) at appropriate doses.

Long and antagonist protocols were following timely use of oral contraceptive pill (Lindynette). Ovarian response to gonadotropins was monitored by transvaginal ultrasound and serum estradiol measurement every second day from Day 7. Ovulation was triggered by human chorionic gonadotropin hCG when the leading follicle reached $18 \mathrm{~mm}$ with appropriate serum E2 levels. Transvaginal oocyte retrieval was scheduled 36 hours and embryo transfer was performed 3 days later. All patients received luteal phase support for 2 weeks. Pregnancies were diagnosed by increasing concentration of serum human chorionic gonadotropin, 14 days after oocyte retrieval. ART results were divided with following outcomes: biochemical pregnancies, live births (singletons, twins) and miscarriages.

\section{Statistical analysis}

Statistical analysis was performed with SPSS 22.0 for Windows. Continuous data were presented like mean and SD and categorical data were presented like number and percentage. Statistical comparisons among groups were performed using the Fisher exact test, Pearson $\chi^{2}$ test for qualitative variables and Mann-Whitney test, KruskalWallis test for quantitative variables. Following, if there were significant differences, authors tested in logistic regression model.

\section{RESULTS}

From 2003 through 2018, 99 endometriosis patients underwent infertility treatment and all of them underwent laparoscopic treatment but only 51 women undergo 287 ART cycles in SIA 'Clinic EGV', Riga, Latvia. Patients characteristics and its relationship with biochemical pregnancy, live birth is shown in Table 1.

In this work, authors did not analyse women separately, but the procedures, because in the end a woman could become pregnant after each procedure. By the word procedure is meant an operation or assisted reproductive technology. One woman could have several treatment strategies. As a result, 99 women completed 167 infertility treatment strategies.

The mean age of women was 34.2 \pm 4.5 . In $89(53.3 \%)$ cases women had primary infertility. In $58(34.7 \%)$ cases women had abortion history. In $90(53,9 \%)$ cases women duration of infertility was $>3$ years. There were significant differences between infertility type (primary 
or secondary) and biochemical pregnancy rate $(\mathrm{p}=0.048)$ and between abortion history and biochemical pregnancy rate $(\mathrm{p}=0.033)$.
Accordingly, there was a significant difference between duration of infertility and biochemical pregnancy rate $(\mathrm{p}=0.001)$ and live birth rate $(\mathrm{p}=0,002)$.

Table 1: Patient characteristics ( $\mathrm{n}=99$ women).

\begin{tabular}{|c|c|c|c|}
\hline \multirow[t]{2}{*}{ Characteristics } & \multirow[t]{2}{*}{ Values } & \multicolumn{2}{|c|}{$\begin{array}{l}\text { Patient characteristics influens on biochemical } \\
\text { pregnancy and live birth }\end{array}$} \\
\hline & & Biochemical pregnancy (p value) & Live birth ( $p$ value) \\
\hline Age & $34.2 \pm 4.5$ & $0.007^{\mathrm{b}}$ & $0.004^{\mathrm{b}}$ \\
\hline Pre pregnant weight & $62,3 \pm 9.3$ & $0.181^{\mathrm{b}}$ & $0.245^{\mathrm{b}}$ \\
\hline Height & $168.0 \pm 5.8$ & $0.710^{\mathrm{b}}$ & $0.928^{\mathrm{b}}$ \\
\hline Pre pregnant body mass index, $\mathrm{kg} / \mathrm{m}^{2}$ & $22.1 \pm 2.9$ & $0.112^{\mathrm{b}}$ & $0.012^{\mathrm{b}}$ \\
\hline Underweight $(\mathrm{BMI}<18.5)$ & $8(8.1 \%)$ & & \\
\hline Healthy weight $(\mathrm{BMI}=18.5-24.99)$ & $75(75.8 \%)$ & & \\
\hline Overweight $(\mathrm{BMI}=25-29.99)$ & $13(13.1 \%)$ & & \\
\hline Obese $(\mathrm{BMI}>30)$ & $3(3.0 \%)$ & & \\
\hline Duration of infertility & & $0.001^{\mathrm{a}}$ & $0.002^{\mathrm{a}}$ \\
\hline$\leq 3$ years & $49(49.5 \%)$ & & \\
\hline$>3$ years & $50(50.5 \%)$ & & \\
\hline Abortion history & $30(30.3 \%)$ & $0.033^{\mathrm{a}}$ & $0.437^{\mathrm{a}}$ \\
\hline Type of infertility & & $0.048^{\mathrm{a}}$ & $0.550^{\mathrm{a}}$ \\
\hline Primary & $62(62.6 \%)$ & & \\
\hline Secondary & $37(37.4 \%)$ & & \\
\hline Associated male factor & $28(28.3 \%)$ & $0.225^{\mathrm{a}}$ & $0.005^{\mathrm{a}}$ \\
\hline Endometriosis phenotype & & $0.015^{\mathrm{a}}$ & $0.317^{\mathrm{a}}$ \\
\hline SUP & $45(45.5 \%)$ & & \\
\hline OMA & $43(43.4 \%)$ & & \\
\hline DIE & $11(11.1 \%)$ & & \\
\hline Endometriosis stage & & $0.630^{\mathrm{a}}$ & $0.791^{\mathrm{a}}$ \\
\hline $\mathrm{I} / \mathrm{II}$ & $43(43.4 \%)$ & & \\
\hline III/IV & $56(56.6 \%)$ & & \\
\hline Number of prior laparoscopic surgeries & $1.2 \pm 0.5$ & $0.043^{\mathrm{a}}$ & $0.044^{\mathrm{a}}$ \\
\hline 1 surgery & $76(76.8 \%)$ & & \\
\hline 2 surgeries & $19(19.2 \%)$ & & \\
\hline 3 surgeries & $4(4.0 \%)$ & & \\
\hline \multicolumn{4}{|l|}{ Ovarian reserve } \\
\hline Day-3 FSH, IU/L & $8.10 \pm 8.0$ & $0.603^{\mathrm{b}}$ & $0.485^{\mathrm{b}}$ \\
\hline Day-3 LH, IU/L & $6.21 \pm 7.0$ & $0.147^{\mathrm{b}}$ & $0.596^{\mathrm{b}}$ \\
\hline Day-3 estradiol, pg/mL & $63.05 \pm 78.88$ & $0.054^{\mathrm{b}}$ & $0.136^{\mathrm{b}}$ \\
\hline
\end{tabular}

Table 2: Endometriosis-associated infertility: pregnancy rate according to different treatment strategies.

\begin{tabular}{|c|c|c|c|}
\hline & $\begin{array}{l}\text { Group } 1 \text { (surgery) } n=56 \\
(33.5 \%) \text { cases }\end{array}$ & $\begin{array}{l}\text { Group } 2 \text { (surgery + ART) } n=111 \\
(66.5 \%) \text { cases }\end{array}$ & P value \\
\hline Age & $30.7 \pm 4.6$ & $35.1 \pm 4.2$ & $0.000^{\mathrm{b}}$ \\
\hline Biochemical pregnancies (n) & $28(50.9 \%)$ & $48(47.5 \%)$ & $0.645^{\mathrm{a}}$ \\
\hline Live birth (n) & $27(48.1 \%)$ & $23(22.77 \%)$ & $0.005^{\mathrm{a}}$ \\
\hline Singletons or twins & & & $0.000^{\mathrm{a}}$ \\
\hline Singletons (n) & 27 & 13 & \\
\hline Twins (n) & 0 & 10 & \\
\hline Abortion (n) & $0(0 \%)$ & $4(3.6 \%)$ & $0.021^{\mathrm{a}}$ \\
\hline
\end{tabular}

a Pearson $\chi^{2}$ test; ${ }^{\mathrm{b}}$ Mann-Whitney test. 
All procedures were divided in two groups depending on the stage of endometriosis. In first group was I/II stages (61 cases) and second group was III/IV stages (96 cases) and 10 cases was missing because these women began to be seen by another gynaecologist, so it was excluded. There were no significant differences between endometriosis stages and biochemical pregnancy (OR, $0.23 ; 95 \% \mathrm{CI}, 0.44-1.62 ; \mathrm{p}=0.630)$ and live birth $(\mathrm{p}=0.791)$. The endometriosis phenotype was as: SUP, 67 cases; OMA, 70 cases; DIE 20 cases and 10 cases was missing so it was excluded. In all cases there was history of laparoscopic surgery for endometriosis with the mean number of surgeries $1.2 \pm 0.5$. There were significant differences between endometriosis phenotype and biochemical pregnancy $(\mathrm{p}=0.015)$, especially biochemical pregnancy rates decreased in OMA, DIE cases compared with SUP (cases with OMA, OR, 5.2; $\operatorname{Exp}(\mathrm{B})$ 0.44; $95 \%$ CI, 0.22-0.88; $\mathrm{p}=0.022$; cases with DIE, OR, 5.6; $\operatorname{Exp}(\mathrm{B})$ 0.27 ; 95\% CI, 0.09-0.79; $\mathrm{p}=0.018$ ), but in live birth rate there were not differences $(p=0.317)$. All procedures were divided in two groups depending on treatment strategy. In first group was only surgery cases, but in second group surgery and ART cases. In 56 (33.5\%) cases was only laparoscopic operation. After laparoscopic operation there were $28(50.9 \%)$ biochemical pregnancies cases and $26(48.1 \%)$ live birth cases. All of them was singleton pregnancy. In $111(66.5 \%)$ cases there were laparoscopic operation and ART procedure. Of which IVF, 41 (24.6\%) cases; ICSI, 40 (24.0\%) cases; FET, 30 $(18.0 \%)$ cases. It is interesting to see the effect of women age on the pregnancy rate of the two therapeutic options. In 1 group patients mean age $30.7 \pm 4.6$ and 2 group with mean age $35.1 \pm 4.2 \quad(p=0.000)$. In total, 51 women underwent 287 ART cycles with 101 embryo transfer. There are significant differences between ART cycle number and biochemical pregnancy $(\mathrm{p}=0.042)$ and between retrieved follicle count and biochemical pregnancy $(p=0.021)$, live birth $(p=0.008)$. Retrieved follicle count was decreased according endometriosis severity stage. In I/II endometriosis stages were retrieved follicle with mean count $14.56 \pm 2.8$ and in III/IV endometriosis stages were retrieved follicle with mean count 11.39 \pm 1.0 . Also, there are significant difference between number of fertilized eggs and live birth $(\mathrm{p}=0.014)$. Overall after ART procedure, $48(47.5 \%)$ was biochemical pregnancy cases and $23(22.77 \%)$ was live birth cases. Pregnancy outcomes are showed in Table 2.

There were no differences between biochemical pregnancy rate according to different endometriosis treatment strategies $(\mathrm{p}=0.343)$. But there was significant difference between live birth rate according to different endometriosis associated infertility treatment strategies $(p=0.005)$. Assisted reproductive technology cases outcomes are showed in Table 3.

As it was already mentioned in all cases women underwent surgery treatment. Some of them even several times: mean 1.2 \pm 0.5 . There was significant difference between laparoscopic operation number and biochemical pregnancy rate $(\mathrm{p}=0.043)$ and live birth rate $(\mathrm{p}=0.044)$.

Table 3: Assisted reproductive technology outcomes ( $n=111$ cases).

\begin{tabular}{|l|l|}
\hline Characteristics & Values \\
\hline IVF cases & $41(36.9 \%)$ \\
\hline ICSI cases & $40(36.0 \%)$ \\
\hline FET cases & $30(27.0 \%)$ \\
\hline ART cycles & 287 \\
\hline 1 cycle & 44 \\
\hline 2 cycles & 26 \\
\hline 3 cycles & 14 \\
\hline 4 cycles & 10 \\
\hline 5 cycles & 6 \\
\hline 6 cycles & 4 \\
\hline 7 cycles & 3 \\
\hline 8 cycles & 2 \\
\hline 9 cycles & 2 \\
\hline Embryo transfers & 101 \\
\hline Biochemical pregnancies & $48(47.5 \%)$ \\
\hline Live birth & $23(22.7 \%)$ \\
\hline Abortion rate & $4 / 48(8.3 \%)$ \\
\hline Live birth rate per cycle & $23 / 287(8.0 \%)$ \\
\hline Live birth rate per embryo transfer & $23 / 101(22.7 \%)$ \\
\hline
\end{tabular}

All cases were divided in 4 groups according to time interval between surgery and ART. First group 0-12 months, second group 13-24 months, third group 25-36 months and fourth group $>36$ months. There is significant difference between time interval between surgery and ART procedure and biochemical pregnancy $(\mathrm{p}=0.004)$ and live birth $(p=0.000)$. In first year after operative surgery is the best pregnancy results. Interesting is that between men factor and biochemical pregnancy is not significant differences $(p=0.225)$, but with live birth is significant differences $(\mathrm{p}=0.005)$. Very similar situation is with BMI. Between BMI and biochemical pregnancy is not significant differences $(p=0.112)$, but with live birth is significant differences $(\mathrm{p}=0.012)$.

\section{DISCUSSION}

Endometriosis is one of the most common gynaecologic pathologies with a well-known negative impact on female fertility. ${ }^{2}$ Women with endometriosis are confronted with one or both of two major problems: endometriosisassociated pain, infertility, or both. For the literature searches, the outcomes included were live birth rate, pregnancy, multiple pregnancy rate, miscarriage rate, ectopic pregnancy, teratogenicity and side effects of treatment. It should be noted that although live birth rate is the most relevant outcome, most studies only report on (biochemical or clinical) pregnancy rates. ${ }^{12}$ The current study focused on the American Society for Reproductive Medicine classification system in four stages: minimal (I), mild (II), moderate (III) and severe (IV) and endometriosis phenotype (1) superficial peritoneal 
endometriosis (SUP), (2) ovarian endometrioma (OMA), and (3) deeply infiltrating endometriosis (DIE). ${ }^{17,18}$ Present results showing that between endometriosis stages and biochemical pregnancy, live birth there is not significant differences, but endometriosis phenotype have impact on biochemical pregnancy rate. The retrospective review of 200 endometriosis patients and IVF outcome pointed that clinical pregnancy rate was significantly lower in deeply infiltrating endometriosis involving the bladder, sigmoid, uterosacral ligaments or vagina. ${ }^{19}$ Conversely, Chloe Maignien reviewed 359 endometriosis cases showed no differences in ART outcome according to disease phenotype. ${ }^{20}$ But a recent meta-analysis from Rossi AC, Prefumo F, review of 980 women with endometriosis and 5934 controls. Clinical pregnancy rates were lower in stage III-IV than controls. ${ }^{21}$ On the contrary, in another meta-analysis from Barbosa et al including 2227 stage I/II endometriosis patients and 1703 stage III/IV patients, no significant difference was found concerning clinical pregnancy rates $(38 \%$ vs $34.2 \%$; relative risk, $0.90 ; 95 \% \mathrm{CI}, 0.82-1.00){ }^{22}$ It is accepted that surgery should be the primary therapeutic option to increase spontaneous pregnancy rates. The use of laparoscopic surgery in the treatment of subfertility related to minimal and mild endometriosis may improve future fertility. ${ }^{23,24}$ In infertile women with ASRM stage III/IV endometriosis, can be offered operative laparoscopy, to increase spontaneous pregnancy rates. ${ }^{25,26}$ All studies agree that IVF/ICSI should be recommended to infertile patients who have not become pregnant after operation for endometriosis. ${ }^{12}$ Infertile women with endometriosis after surgery can be offered ART, since endometriosis recurrence rates are not increased after ovarian stimulation for ART. ${ }^{27,28}$ The interval from endometriosis surgery to ART had a significant effect on the biochemical pregnancy rate and live birth rate in present study. The highest biochemical pregnancy was achieved in patients who underwent their ART cycle in first year after their surgery. So, ART may be considered to around 12 months from endometriosis surgery. Previous studies found significant effect of the interval from surgery and IVF and highest ongoing pregnancy rate was achieved in patients who underwent their IVF cycle 6 to 25 months after their endometriosis surgery. ${ }^{29}$ Also, Nesbitt-Hawes et al. have reported that a median time to conception was 12 months. ${ }^{30}$ But some studies found no effect of the interval between surgery and IVF on the pregnancy rate. ${ }^{31,32}$ It is interesting to see the effect of women age on the pregnancy rate of the two therapeutic options. The similar results reported Pedro $\mathrm{N}$ Barri et al. ${ }^{33}$ Several studies demonstrate that longer the duration of infertility that lowers the pregnancy rates. ${ }^{34}$ Really, Nuoja-Huttunen et al. found decreased pregnancy rates in couples with an infertility period $\geq 6$ years. ${ }^{35}$ While some studies have shown that secondary infertility have positive effect on pregnancy rate, another studies don't show such relationship. ${ }^{36,37}$ In present study there is significant difference between laparoscopic surgery number and biochemical pregnancy rate. Perhaps this could be explained by the fact that during the endometrioma operation decreases ovarian reserve and this decreases pregnancy rate. Berlanda $\mathrm{N}$ has reported that after repeating conservative surgery for infertility, the pregnancy rate is almost half the rate obtained after primary surgery. ${ }^{38}$ In present work there is significant difference between different treatment strategies and abortion rate $(p=0.021)$. It increased in group with ART. Omland et al. has noticed that The spontaneous first trimester loss rate prior to gestational week 6 was significantly higher in the endometriosis group compared with the unexplained group. ${ }^{8}$ According to the literature, there is insufficient evidence for an association between endometriosis and (recurrent) miscarriage, but there is, however, epidemiological evidence to support the link between endometriosis and recurrent implantation failure after assisted reproduction. This can possibly be explained by alterations in humoral and cell-mediated immunity in women with endometriosis. ${ }^{39}$ Number of retrieved oocytes differed between patients with ASRM I/II and III/IV endometriosis. This finding of an ovarian response in subjects with ASRM III-IV endometriosis confirms prior report. ${ }^{40}$

\section{CONCLUSION}

In conclusion, patients with endometriosis related infertility should undergo surgical treatment as the primary option. Those patients who do not become pregnant after surgery must be treated with assisted reproductive technology help. The combination of laparoscopic surgery and ART offers the best chance of pregnancy. The optimal time to perform ART is first year after endometriosis surgery. Then will be the best ART outcome. It was found that there is significant difference between endometriosis phenotype, infertility type, duration of infertility, repeated laparoscopic surgery, ART cycles, retrieved oocyte count and biochemical pregnancy rate.

\section{ACKNOWLEDGMENTS}

Authors would like to thank Dr. Vija Silina and Dr. Zane Vìtina for their help in this publication.

\section{Funding: No funding sources}

Conflict of interest: None declared

Ethical approval: The study was approved by the local ethics committee (Riga Stradiņš University ethics committee)

\section{REFERENCES}

1. Kennedy S, Bergqvist A, Chapron C, D'Hooghe T, Dunselman G, Greb R, et al. ESHRE guideline for the diagnosis and treatment of endometriosis. Hum Reprod. 2005;20:2698-704.

2. Eskenazi B, Warner ML. Epidemiology of endometriosis. Obstet Gynecol Clin North Am. 1997;24:235-58. 
3. Meuleman C, Vandenabeele B, Fieuws S, Spiessens C, Timmerman D, D'Hooghe T. High prevalence of endometriosis in infertile women with normal ovulation and normospermic partners. Fertil Steril. 2009;92:68-74.

4. de Ziegler D, Borghese B, Chapron C. Endometriosis and infertility: pathophysiology and management. Lancet. 2010;376:730-8.

5. Johnson NP, Hummelshoj L, Adamson GD, Keckstein J, Taylor HS, Abrao MS, et al. World Endometriosis Society consensus on the classification of endometriosis. Hum Reprod. 2017;32(2):315-24.

6. Jacobson TZ, Duffy JM, Barlow DH, Farquhar C, Koninckx PR, Olive D. Laparoscopic surgery for subfertility associated with endometriosis. Cochrane Database of Systematic Reviews. 2010(1):CD001398.

7. Shimizu Y, Takashima A, Takahashi K, Kita N, Fujiwara M, Murakami T. Long-term outcome, including pregnancy rate, recurrence rate and ovarian reserve, after laparoscopic laser ablation surgery in infertile women with endometrioma. J Obstet Gynaecol Res. 2010;36(1):115-8.

8. Omland AK, Åbyholm T, Fedorcsák P, Ertzeid G, Oldereid NB, Bjercke S, et al. Pregnancy outcome after IVF and ICSI in unexplained endometriosisassociated and tubal factor infertility. Hum Reprod. 2005;20:722-7.

9. Stephansson O, Kieler H, Granath F, Falconer H. Endometriosis, assisted reproductive technology, and risk of adverse pregnancy outcome. Hum Reprod. 2009;24:2341-7.

10. Zhang X, Liu D, Huang W, Wang Q, Feng X, Tan J. Prediction of Endometriosis Fertility Index in patients with endometriosis-associated infertility after laparoscopic treatment. Reprod Biomed Online. 2018;37(1):53-59.

11. Ramirez KH. Comparisons between laparoscopy only versus in vitro fertilization in combination with laparoscopy for increasing probability of pregnancy in patients with endometriosis associated infertility. School of Physician Assistant Studies; 2012(274). Available at: http://commons.pacificu.edu/pa/274.

12. Guideline on the management of women with endometriosis, 2013. Available at: https://www.eshre.eu/Guidelines-andLegal/Guidelines/Endometriosis-guideline

13. Hamdan M, Omar SZ, Dunselman G, Cheong Y. Influence of endometriosis on assisted reproductive technology outcomes: a systematic review and metaanalysis. Obstet Gynecol. 2015;125:79-88.

14. Kuivasaari P, Hippelainen M, Anttila M, Heinonen S. Effect of endometriosis on IVF/ICSI outcome: stage III/IV endometriosis worsens cumulative pregnancy and live-born rates. Hum Reprod. 2005;20:3130-5.

15. Polat M, Boynukalin FK, Yarali I, Esinler I, Yarali H. Endometriosis is not associated with inferior pregnancy rates in in vitro fertilization: an analysis of 616 patients. Gynecol Obstet Invest. 2014;78:59-64.

16. Singh N, Lata K, Naha M, Malhotra N, Tiwari A, Vanamail P. Effect of endometriosis on implantation rates when compared to tubal factor in fresh non donor in vitro fertilization cycles. J Hum Reprod Sci. 2014;7:143-7.

17. Elsevier Science Inc. Revised American Society for Reproductive Medicine classification of endometriosis: 1996. Fertility and Sterility. 1997;67(5). Available at: https://doi.org/10.1016/S0015-0282(97)81391-X.

18. Nisolle M, Donnez J. Peritoneal endometriosis, ovarian endometriosis, and adenomyotic nodules of the rectovaginal septum are three different entities. Fertil Steril. 1997;68:585-96.

19. Agnani G, Collin A, Dellis X, Lagré P, Souquet C, Roux C. Endometriosis severity and IVF outcome. Fertil Steril. 2008;90:S408.

20. Maignien C, Santulli P, Gayet V, Lafay-Pillet MC, Korb D, Bourdon $\mathrm{M}$, et al. Prognostic factors for assisted reproductive technology in women with endometriosis-related infertility. Am J Obstet Gynecol. 2017;216(3):280-e1.

21. Rossi AC, Prefumo F. The effects of surgery for endometriosis on pregnancy outcomes following in vitro fertilization and embryo transfer: a systematic review and meta-analysis. Arch Gynecol Obstet. 2016;294:647-55.

22. Barbosa MA, Teixeira DM, Navarro PA, Ferriani RA, Nastri CO, Martins WP. Impact of endometriosis and its staging on assisted reproduction outcome: systematic review and metaanalysis. Ultrasound Obstet Gynecol. 2014;44:26178.

23. Jacobson TZ, Duffy JM, Barlow D, Farquhar C, Koninckx PR, Olive D. Laparoscopic surgery for subfertility associated with endometriosis. Cochrane Database Syst Rev. 2010:CD001398.

24. Nowroozi K, Chase JS, Check JH, Wu CH. The importance of laparoscopic coagulation of mild endometriosis in infertile women. Int $\mathbf{J}$ Fertil, 1987;32:442-4.

25. Nezhat C, Crowgey S, Nezhat F. Videolaseroscopy for the treatment of endometriosis associated with infertility. Fertil Steril. 1989;51:237-40.

26. Vercellini P, Fedele L, Aimi G, De Giorgi O, Consonni D, Crosignani PG. Reproductive performance, pain recurrence and disease relapse after conservative surgical treatment for endometriosis: the predictive value of the current classification system. Hum Reprod. 2006;21:267985.

27. Benaglia L, Somigliana E, Santi G, Scarduelli C, Ragni G, Fedele L. IVF and endometriosis-related symptom progression: insights from a prospective study. Hum Reprod. 2011;26:2368-72.

28. Coccia ME, Rizzello F, Gianfranco S. Does controlled ovarian hyperstimulation in women with a 
history of endometriosis influence recurrence rate? J Womens Health, 2010;19:2063-9.

29. AlKudmani B, Gat I, Buell D, Salman J, Zohni K, Librach $\mathrm{C}$, et al. In vitro fertilization success rates after surgically treated endometriosis and effect of time interval between surgery and in vitro fertilization. J Minimally Invasive Gynecol. 2018;25(1):99-104.

30. Nesbitt-Hawes EM, Campbell N, Maley PE, Won H, Hooshmand D, Henry A, et al. The surgical treatment of severe endometriosis positively affects the chance of natural or assisted pregnancy postoperatively. BioMed Res Int. 2015;2015.

31. Bedaiwy MA, Falcone T, Katz E, Goldberg JM, Assad R, Thornton J. Association between time from endometriosis surgery and outcome of in vitro fertilization cycles. J Reprod Med. 2008;53:161-5.

32. Huang XW, Qiao J, Xia EL, Ma YM, Wang Y. Effect of interval after surgery on in vitro fertilization/ intracytoplasmic sperm injection outcomes in patients with stage III/IV endometriosis. Chin Med J. 2010;123:2176-80.

33. Barri PN, Coroleu B, Tur R, Barri-Soldevila PN, Rodríguez I. Endometriosis-associated infertility: surgery and IVF, a comprehensive therapeutic approach. Reprod Biomed Online. 2010;21(2):17985 .

34. Erdem A, Erdem M, Atmaca S, Korucuoglu U, Karabacak O. Factors affecting live birth rate in intrauterine insemination cycles with recombinant gonadotrophin stimulation. Reprod Biomed Online. 2008;17:199-206.

35. Nuojua-Huttunen S, Tomas C, Bloigu R, Tuomivaara L, Martikainen $\mathrm{H}$. Intrauterine insemination treatment in subfertility: an analysis of factors affecting outcome. Hum Reprod. 1999;14:698-703.

36. Dinelli L, Courbière B, Achard V, Jouve E, Deveze C, Gnisci A, et al. Prognostis factors of pregnancy after intrauterine insemination with the husband's sperm: conclusions of an analysis of 2,019 cycles. Fertil Steril. 2014;101:994-1000.

37. Steures P, van der Steeg JW, Mol BW, Eijkemans MJ, van der Veen F, Habbema JD, et al. CECERM (Collaborative Effort in Clinical Evaluation in Reproductive Medicine). Prediction of an ongoing pregnancy after intrauterine insemination. Fertil Steril. 2004;82:45-51.

38. Berlanda N, Vercellini P, Fedele L. The outcomes of repeat surgery for recurrent symptomatic endometriosis. Current Opinion Obstet Gynecol. 2010;22(4):320-5.

39. Tomassetti C, Meuleman C, Pexsters A, Mihalyi A, Kyama C, Simsa P, et al. Endometriosis, recurrent miscarriage and implantation failure: is there an immunological link? Reprod BioMed Online. 2006;13(1):58-64.

40. Al-Fadhli R, Kelly SM, Tulandi T, Tanr SL. Effects of different stages of endometriosis on the outcome of in vitro fertilization. J Obstet Gynaecol Can. 2006;28:888-91.

Cite this article as: Avdotina J, Mezecka-Oleinika A, Silina V, Vitina Z. Pregnancy and live birth rates in women with endometriosis related infertility in Latvia. Int J Reprod Contracept Obstet Gynecol 2019;8:808-14. 